\title{
STRATEGI KESANTUNAN DALAM DEBAT CAWAPRES PERIODE 2014 s.d. 2019 DI TV ONE BERDASARKAN PENDEKATAN BROWN DAN LEVINSON
}

\author{
Nur Ainun Makkiyah, Taufik Nurhadi \\ (Bahasa dan Sastra Indonesia, Fakultas Keguruan dan Ilmu Pendidikan, Universitas PGRI \\ Adi Buana Surabaya) \\ nurainunmakkiyah@gmail.com, taufiknurhadi70@gmail.com
}

\begin{abstract}
This research is motivated by the fact that the use of languageis polite to the people who have an important role for Indonesia it is very important due to the smoothness and harmony and to establish intimacy between the narrator and the opponent. The formulation of the problem in this research is "How politeness between Hatta Rajasa and Jusuf Kalla on TV One in the candidate Vice President debate period2014-2019 based on the approach of Brown and Levinson? ". The aim or the purpose is to describe the linguistic politeness Hatta Rajasa and Vice President Jusuf Kalla in the debate vice president debate on TV One based approach Brown and Levinson. This study used a qualitative approach. The data in this study were obtained from the candidate Vice President debate sentences containing linguistic politeness strategies according to Brown and Levinson. Source of data in this study, candidate vice president debate. Data collection techniques in this research that usesrefer methods, tapping techniques, and use advanced techniques is (SBLC). Based on the findings and the discussion has been described in chapter IV, it can be concluded that politeness strategies according to Brown and Levinson include (1) Bald-on Strategy (Without Strategy), (2) Positive Politeness Strategy (familiarity), (3) Negative Politeness Strategy (Formalities), and (4) Off-record Politeness Strategy (Strategy of indirect or fuzzy.
\end{abstract}

Keywords : Politeness Language and Politeness, Strategies Brown and Levinson

\section{PENDAHULUAN}

Kesantunan berbahasa merupakan suatu aspek kebahasaan yang dapat meningkatkan kecerdasan emosional dalam kegiatan bertutur. Karena dalam bertutur atau berkomunikasi antara penutur dan mitra tutur tidak hanya sematamata untuk menyampaikan pesan atau berbicara seadanya, namun juga harus menciptakan suasana yang harmonis dalam hubungan bertutur. Keharmonisan hubungan dalam berkomunikasi antara penutur dan mitra tutur akan tetap terjaga apabila masing-masing saling menghormati dan tidak ada yang saling menjatuhkan.

Kesantunan berbahasa dalam berkomunikasi dengan seseorang atau lawan tutur yang berbeda tingkatannya dibutuhkan penggunaan bahasa yang santun dan sopan agar tercipta rasa saling menghargai antar penutur dan lawan tutur. Tak jarang dalam berbicara atau berkomunikasi seseorang kurang memerhatikan cara berbahasa yang santun dan sopan. Penutur cenderung menggunakan bahasa yang secara umum digunakan dalam kehidupan sehari-hari dengan siapa saja lawan tuturnya. Kesantunan berbahasa sangatlah penting dalam berbicara atau berkomunikasi dengan lawan tutur baik yang sederajat maupun yang di atasnya. 
Dengan demikian, Kesantunan berbahasa adalah kesopanan dan kehalusan dalam menggunakan bahasa ketika berkomunikasi melalui lisan maupun tulisan. Penggunaan bahasa yang sekadarnya dan ceplas ceplos tak terkontrol serta emosional yang tinggi sangat berdampak pada kesantunan dan etika dalam berbahasa yang baik dan sopan. Pentingnya dalam berbahasa secara santun itu akan berdampak pada diri sendiri. Dengan menggunakan bahasa yang santun dan tidak menyinggung perasaan orang lain dalam berpendapat atau bertutur kata, baik itu dengan lawan tutur atau maupun dalam suatu forum yang bersifat formal seperti rapat atau debat misalnya, maka akan merasa dihargai oleh orang lain atau lawan tutur.

Melihat paparan di atas, penelitian ini ingin menjawab permasalahan, bagaimana kesantunan berbahasa antara Jusuf Kalla dan Hatta Rajasa di TV One dalam rangka Debat Presiden Periode 2014-2019 berdasarkan pendekatan Brown and Levinson? Yang hasilnya diharapkan mampu mengevaluasi mahasiswa khususnya mahasiswa jurusan bahasa dan sastra Indonesia dalam berbahasa dengan menggunakan bahasa yang santun baik itu dengan sebaya maupun dengan orang yang lebih tua/tinggi derajatnya. Selain itu juga untuk mengolah kemampuan berbahasa seseorang agar mampu berbahasa secara santun sehingga tidak menyinggung perasaan mitra tutur.

Dengan demikian, penelitian ini bertujuan untuk mengetahui atau mendeskripsikan kesantunan berbahasa antara Jusuf Kalla dan Hatta Rajasa di TV One dalam rangka Debat Presiden Periode 2014-2019 berdasarkan pendekatan Brown and Levinson.

\section{METODE PENELITIAN}

Penelitian ini merupakan penelitian kualitatif. Maleong, (2007: 6) definisi penelitian kualitatif yaitu penelitian yang bermaksud untuk memahami fenomena tentang apa yang dialami oleh subjek penelitian secara holistic, dan dengan cara deskripsi dalam bentuk kata-kata dan bahasa pada suatu konteks khusus yang alamiah dan dengan memanfaatkan berbagai metode ilmiah. Penelitian ini bertujuan untuk mengetahui atau mendeskripsikan kesantunan berbahasa antara Jusuf Kalla dan Hatta Rajasa di TV One dalam rangka Debat Presiden Periode 2014-2019 berdasarkan pendekatan Brown and Levinson. Data dalam penelitian ini diperoleh dari kalimat dalam debat Cawapres yang mengandung strategi kesantunan berbahasa menurut Brown dan Levinson. Sumber data dalam penelitian ini yaitu debat cawapres periode 2014-2019 di Tv One yang telah diunduh melalui youtobe pada tanggal 12 Agustus 2014. Teknik pengumpulan data dalam penelitian ini yaitu menggunakan metode simak, teknik sadap, lalu menggunakan teknik lanjutan yaitu (SBLC). Setelah itu teknik rekam/download yang kemudian dilanjutkan dengan teknik catat. Teknik analisis data yang digunakan dalam penelitian ini yaitu analisis deskriptif yang memberikan gambaran dengan jelas dan benar.

Berdasarkan hasil temuan penelitian dan pembahasan yang telah dijelaskan pada bab IV dapat disimpulkan bahwa strategi kesantunan berbahasa menurut Brown dan Levinson meliputi (1) Bald-on Strategy (Tanpa Strategi), (2) Positive Politeness Strategy (Strategi Kesantunan Positif/ Keakraban), (3) 
Negative Politeness Strategy (Strategi Kesantuan Negatif/ Formalitas), dan (4) Off-record Politeness Strategy (Strategi Tidak Langsung atau Tersamar.

\section{HASIL PENELITIAN}

Berikut merupakan analisis percakapan Hatta Rajasa dengan Jusuf Kalla dalam peristiwa debat cawapres di TV One berdasarkan analisis menggunakan kriteria strategi kesantunan berbahasa Brown and Levinson yang terdiri dari empat hal yaitu (1) Bald-on RecordStrategy (tanpa strategi), (2) Positive politeness strategy (strategi kesantunanpositif/ keakraban), (3) Negative politeness strategy (strategi kesantunan negatif/ formal), dan (4) Off-record politeness strategy (strategi tidak langsung atau tersamar).

\section{Bald-on Record Strategy (Tanpa Strategi)}

"Pertama-tama, izinkanlah saya menyampaikan selamat menunaikan Ibadah Puasa kepada seluruh umat muslimin dan muslimat di seluruh tanah air." (HR001)/Prg.3/TS/Seg1

Tuturan ini disampaikan oleh Hatta Rajasa sebagai pembicara pertama dalam debat cawapres di TV One. Dalam tuturan di atas terdapat ucapan "izinkanlah saya menyampaikan selamat menunaikan ibadah puasa..." yang dilontarkan oleh Hatta Rajasa dalam debatnya. Dengan mengucapkan demikian, Hatta Rajasa tidak meminimalisir ancaman bagi muka lawan tuturnya untuk mengurangi akibat dari tindakan yang mengancam muka. Sudah bukan hal yang asing lagi untuk mengucapkan atau menyampaikan ucapan selamat menunaikan ibadah puasa dan ini merupakan hal yang wajar dan umum adanya, lalu mengapa Hatta Rajasa mengucapkannya dengan meminta izin terlebih dahulu. dari sinilah tindakan yang dilakukan oleh Hatta Rajasa yang berupa instruksi.

"Pertanyaanya, apakah kebijakan mengirim tenaga TKI itu masih de..dipertimbangkan? atau dilanjutkan atau dihentikan, bagaimana menurut pendapat Pak Hatta?" (JK010)/Prg.2/TS/Seg4

Tuturan ini disampaikan oleh Jusuf Kalla sebagai pembicara kedua dalam debat cawapres di TV One. Dalam tuturan di atas, Jusuf Kalla mengajukan pertanyaan tanpa terlebih dahulu mendapat perintah atau aba-aba dari moderator. Hal ini mengakibatkan lawan tutur (Hatta Rajasa) merasa terkejut atau keget, dan tidak nyaman karena waktu yang mungkin sangat singkat, akan tetapi moderator telah memberikan waktu untuk Hatta Rajasa menjawabnya dalam waktu dua menit.

\section{Positive Politeness Strategy (Strategi Kesantunan Positif/ Keakraban)}

"Pak JK kan sudah faham juga, bahwa kita sebetulnya sesungguhnya sudah berswasembada pangan beras." (HR015)/Prg.2/SKP/Seg6

Tuturan ini disampaikan oleh Hatta Rajasa selaku pembicara pertama dalam debat cawapres di TV One. Dalam tuturan di atas, Hatta Rajasa memberikan perhatian kepada lawan tuturnya yaitu Jusuf Kalla dengan menyebutkan namanya yaitu "Pak $J K$ " serta penggunaan kata "kita" yang membuat mereka terlihat begitu akrab. Selain itu Hatta Rajasa juga terlihat memusatkan perhatiannya pada lawan tuturnya yaitu Jusuf Kalla. 
"Saudara sekalian yang saya cintai, Pembukaan Undang-Undang Dasar 1945 mengamanatkan kepada kita, bahwa kita mencerdaskan kehidupan bangsa." (HR001)/Prg.4/SKP/Seg1

Tuturan ini disampaikan oleh Hatta Rajasa sebagai pembicara pertama dalam peristiwa debat cawapres di TV One. Tuturan di atas termasuk dalam kesantunan berbahasa kategori menggunakan penanda keakraban kelompok. Hal ini dapat dibuktikan dengan penggunaan kata "cinta" yang diucapkan kepada semua dan menganggap semua orang adalah saudara sebagai penanda keakraban kelompok dan bertujuan untuk lebih mengakrabkan antar sesama walau belum begitu dekat, dengan nama lain yaitu salam hangat bagi semua.

\section{Negative politeness strategy (strategi kesantunan negatif/ formalitas)}

"Tentu saja Bapak JK yang terhormat, koordinasi harus dilakukan." (HR019)/Prg.1/SKN/Seg6

Tuturan ini dikemukakan oleh Hatta Rajasa selaku pembicara pertama dalam debat cawapres di TV One. Tuturan yang disampaikan oleh Hatta Rajasa di atas merupakan sikap saling menghargai terhadap lawan tuturnya. Hatta Rajasa menunjukkan rasa hormat terhadap lawan tuturnya yaitu Jusuf Kalla dengan menggunakan kata "yang terhormat". Kata tersebut menunjukkan arti rasa saling menghargai terutama kepada orang yang lebih tua.

"Ya, revolusi jangan Anda salah artikan seakan-akan suatu pemberontakan, tidak......bangsa." (JK007)/Prg.1/SKN/Seg4

Tuturan ini dikemukakan oleh Jusuf Kalla sebagai pembicara kedua dalam debat cawapres di TV One. Bentuk tuturan yang disampaikan oleh Jusuf Kalla dalam kutipan di atas merupakan sebuah pengelakan atau membantah serta berusaha membenarkan atas dugaan atau pendapat dari Hatta Rajasa yang menurut Jusuf Kalla tidak benar. Hal ini dapat dibuktikan pada kalimat "revolusi jangan Anda salah artikan seakan-akan suatu pemberontakan, tidak...". Pada kalimat ini Jusuf Kalla berusaha untuk meluruskan sesuatu yang tidak benar dalam perdebatan dengan menjelaskan secara detail.

\section{Off-record Politeness Strategy (Strategi Tidak Langsung atau Tersamar)}

"Karena itulah, kita semua, Pak Jokowi selalu mengatakan bahwa yang pertama itu dilaksanakan adalah meningkatkan derajat sumberdaya manusia kita." (JK002)/Prg.4/STL/Seg1

Tuturan ini dikemukakan oleh Jusuf Kalla sebagai pembicara kedua dalam debat cawapres di TV One. Bentuk tuturan yang disampaikan oleh Jusuf Kalla dalam kutipan di atas merupakan bentuk tindakan mengancam muka namun beliau tidak ingin bertanggung jawab atas tindakan itu. Hal ini dapat dibuktikan dengan setelah mengatakan "kita semua" beliau mengikutsertakan "pak Jokowi", hal ini sangat jelas bahwa beliau tidak ingin bertanggung jawab atas tindakan mengancam muka tersebut.

"Akan tetapi kalau yang dimaksud adalah, mengapa kita mengimpor minyak? Pak JK kan bagian dari pemerintahan KIB I, tahu mengapa, mengapa kita mengimpor minyak." (HR011)/Prg.1/STL/Seg5

Tuturan ini dikemukakan oleh Hatta Rajasa sebagai pembicara pertama dalam debat cawapres di TV One. Bentuk tuturan yang disampaikan oleh Hatta Rajasa di atas merupakan tindakan yang membiarkan lawan tuturnya 
menginterpretasikan sendiri suatu tindakan. Hal ini dapat dibuktikan pada kalimat "Pak JK kan bagian dari pemerintahan KIB I, tahu mengapa, mengapa kita mengimpor minyak." Dengan Hatta Rajasa mengatakan seperti itu maka otomatis lawan tuturnya yaitu Jusuf Kalla memahami dan berpikir sendiri apa yang telah terjadi selama masa pemerintahan Jusuf Kalla.

\section{PEMBAHASAN}

Kesantunan berbahasa merupakan cara berbicara dan berkomunikasi dengan seseorang menggunakan bahasa yang halus, sopan dan santun serta tidak menyinggung perasaan lawan tuturnya. Dalam skripsi ini, saya membahas tentang kesantunan berbahasa dalam kaitannya dengan studi pragmatik. Data yang saya analisis yaitu berupa video debat cawapres di TV One yang telah saya unduh melalui youtobe dan kemudian ditranskrip dalam bentuk tulisan tersirat berisi sederetan percakapan antara cawapres Hatta Rajasa dengan cawapres Jusuf Kalla yang juga dipandu oleh ibu moderator agar proses debat dapat berjalan dengan lancar.

Dalam menganalisis data yang berupa transkrip percakapan debat cawapres di TV One ini, saya menggunakan teori Brown dan Levinson. Pada teori ini, kesantunan berbahasa tersebut berkisar atas dua wajah atau muka, yaitu muka negatif dan muka positif. Pengertian atau maksud muka di sini bukan sekedar muka yang memiliki makna denotasi, namun pengertian muka dalam konteks ini yaitu setiap orang pasti memiliki wajah/ muka. Muka tersebut harus dijaga dari ancaman ketidaksantunan dalam berbahasa. Muncul kata atau istilah kehilangan muka disebabkan oleh seseorang itu tidak dapat menjaga muka dalam bertutur kata yang baik dan santun.

Namun dalam menganalisis transkrip debat cawapres di Tv One ini saya tidak menggunakan teori wajah positif dan wajah negatif, tetapi menggunakan strategi kesantunan berbahasa menurut Brown dan Levinson. Strategi kesantunan Brown dan Levinson terdiri atas empat strategi yaitu diantaranya : (1) Bald-on RecordStrategy (tanpa strategi), (2) Positive politeness strategy (strategi kesantunanpositif/ keakraban), (3) Negative politeness strategy (strategi kesantunan negatif/ formal), dan (4) Off-record politeness strategy (strategi tidak langsung atau tersamar).

Strategi kesantunan Brown dan Levinson yang pertama yaitu tanpa strategi. Dalam debat cawapres Hatta Rajasa dan Jusuf Kalla di TV One ada yang menggunakan strategi yang pertama ini (tanpa strategi) namun tidak banyak. Hanya ada tiga kutipan yang termasuk dalam tanpa strategi ini. Hal ini dikarenakan penggunaan tanpa strategi ini hanya untuk penutur dan lawan tuturnya yang mempunyai hubungan yang erat seperti antar sesama teman dan antar anggota keluarga. Sedangkan dalam debat ini, penutur dan lawan tuturnya hanya masing-masing tim yang berbeda dan saling bersaing dalam mendapatkan posisi di Indonesia.

Strategi kesantunan yang paling sering ditemukan dalam transkrip debat cawapres ini yaitu strategi kesantunan positif dan strategi kesantunan negatif karena pengkategorian strategi kesantunan positif dan negatif ini cukuplah banyak. Namun perlu diketahui bahwa strategi kesantunan negatif di sini bukan berarti buruk atau jelek dalam bertutur kata tetapi merupakan lawan dari positif itu sendiri. Perbandingan antara strategi kesantunan positif dan strategi kesantunan 
negatif yang terdapat dalam transkrip debat cawapres di TV One ini lebih dominan dan paling banyak menggunakan strategi kesantunan positif. Selain pengkategoriannya yang cukup banyak juga forum dalam debat yang disaksikan oleh orang petinggi- petinggi serta ditonton oleh seluruh rakyat Indonesia yang mengharuskan kedua cawapres tersebut menggunakan bahasa yang halus dan sopan dalam menyampaikan pendapatnya. Apabila dilihat dari cara penyampaian dan perbedaan masing-masing pendapat serta cara berpikirnya yaitu lebih jelas dan mengena cara berpendapat Hatta Rajasa daripada Jusuf Kalla. Hal ini bisa disebabkan oleh faktor usia dan penguasaan bahasa masing-masing cawapres. Hatta Rajasa terkesan berwibawa serta lantang dalam menyampaikan pendapatnya sedangkan Jusuf Kalla terkesan berbelit-belit dan sukar untuk dicerna pendapatnya.

Sedangkan strategi kesantunan Brown dan Levinson yang keempat yaitu strategi tidak langsung atau tersamar. Sama halnya dengan tanpa strategi, strategi ini jarang ditemukan dalam transkrip debat cawapres. Hanya terdapat tiga kutipan yang menunjukkan bahwa termasuk dalam kategori strategi tidak langsung/ tersamar. Dalam strategi ini penutur membiarkan lawan tuturnya untuk menginterpretasi sendiri suatu tindakan dan penutur juga melakukan tindakan mengancam muka namun tak ingin bertanggung jawab atas tindakan tersebut.

\section{SIMPULAN}

Berdasarkan hasil temuan penelitian dan pembahasan yang telah dijelaskan pada bab IV dapat disimpulkan bahwa strategi kesantunan Brown dan Levinson meliputi (1) Bald-on Record Strategy (tanpa strategi), (2) Positive Politeness Strategy (strategi kesantunan positif/ keakraban), (3) Negative Politeness Strategy (strategi kesantunan negatif/ formalitas), dan (4) Off-record Politeness Strategy (strategi tidak langsung/ tersamar).

Semakin tinggi derajat/ kedudukan seseorang maka tuntutan untuk menggunakan bahasa yang santun sangatlah wajib dan diperlukan agar terhindar dari bentuk atau istilah kehilangan muka. Dengan demikian, kesantunan dalam berbahasa sangat berperan penting dalam menjalin komunikasi dengan lawan tutur yang sederajat maupun yang berbeda tingkatannya agar penutur dan lawan tutur dapat menjalin hubungan yang baik dan saling menghargai satu sama lain.

\section{SARAN}

Kesantunan berbahasa mempunyai peranan penting dalam hal berinteraksi atau berkomunikasi antara penutur dan lawan tutur. Kesantunan dalam berbahasa dapat membuat dirinya atau penutur merasa dihargai dan juga lawan tutur tidak akan mudah tersinggung dengan bentuk tuturan kita. Dalam hal ini, pemahaman mengenai kesantunan berbahasa diharapkan penulis mampu berbicara dengan baik, halus dan sopan dengan lawan tuturnya, baik lawan tutur itu sederajat maupun yang lebih tua dari kita agar diantara keduanya tercipta rasa saling menghargai satu sama lain serta terhindar dari tindakan ancaman muka.

\section{DAFTAR PUSTAKA}

Chaer, Abdul. 2010. Kesantunan Berbahasa. Jakarta: RinekaCipta. 
http://pembelajaran-mas-dewantara.blogspot.com/2012/04/implikatur percakapan.html. "ImplikaturPercakapan". Diakses atau diunduh, April 2012.

Leech, Geoffrey. 1983. Prinsip-prinsip Pragmatik. Jakarta: Universitas Indonesia.

Mahsun. 2012. Metode Penelitian Bahasa: Tahapan strategi, metode, dan tekniknya. Jakarta: Raja Grafindo Persada.

Moleong, J. Lexy. 2011. Metodologi Penelitian Kualitatif. Bandung: PT Remaja Rosdakarya.

Muhammad. 2011. Metode Penelitian Bahasa. Yogyakarta: AR: Ruzz Media.

Nadar, F.X. 2013. Pragmatik dan Penelitian Pragmatik. Yogyakarta: Graha Ilmu.

Pranowo. 2009. Kesantunan Berbahasa Tokoh Masyarakat Ditinjau dari Aspek Pragmatik. Yogyakarta: Universitas Sanata Dharma. 2012. Berbahasa Secara Santun. Yogyakarta: Pustaka Pelajar.

Rahardi, Kunjana. 2008. Pragmatik: Kesantunan Imperatif Bahasa Indonesia. Jakarta: Penerbit Erlangga.

Sudaryanto. 1988. Metode Linguistik Bagian Kedua Mrtode dan Aneka Teknik Pengumpulan Data. Yogyakarta: Gadja Mada University Press.

Tarigan, Henry Guntur. 2009. Pengajaran Pragmatik. Bandung: Penerbit Angkasa Bandung.

UNIMED-Article-23611-Elvi syahrin.pdf- Adobe Reader

Yule, George. 2006. Pragmatik. Yogyakarta: Pustaka Pelajar. 